\title{
SOLUÇÕES ERGONÔMICAS PARA O DESIGN DE SIMULADORES DE VÔO EM AMBIENTE IMERSIVO DE REALIDADE VIRTUAL ${ }^{1}$
}

\author{
Alexandre Amorim dos Reis ${ }^{2}$, Alexandre Santos Turozi ${ }^{3}$, José Serafim \\ Júnior, Elton Moura Nickel ${ }^{4}$, Felipe Dausacker da Cunha ${ }^{5}$, Ricardo \\ Antônio Álvares da Silva ${ }^{6}$
}

Palavras-chave: Ergonomia, simuladores, realidade virtual

Resumo: O presente artigo comunica resultados de um projeto de pesquisa em design industrial, na busca de soluções para um módulo simulador de vôo de operação em realidade virtual, com ênfase nos problemas ergonômicos evidenciados que envolvem as interações imersivas físicas e virtuais, considerando os aspectos materiais e produtivos especificados.

\section{Introdução}

Esta pesquisa é mantida com recursos do CNPq (auxílio pesquisa-universal e auxílio integrado-bolsas DTI e ITI), da FAPESC (bolsas de iniciação científica PMUC e auxílio pesquisa-universal) e da UDESC, em aprofundamento de pesquisa anterior que envolvia também o Departamento de Engenharia Mecânica da Universidade Federal de Santa Catarina.

O sistema simulador compõe-se por três subsistemas integrados: a) o módulo mecânico que inclui o sistema de acionamento eletromecânico; b) o subsistema de controle de movimento que comanda os movimentos de modo sincronizado e; c) o subsistema de realidade virtual (RV), que executa a simulação do veículo de acordo com o ambiente em que se insere. Quatro elementos estruturais básicos são concebidos para o módulo mecânico, ilustrado na figura 1: a) um garfo com giro segundo o eixo A (Vertical); b) um anel (externo) com giro segundo o eixo B (Horizontal) articulado no garfo; c) uma cabine (bolha) cujo interior deverá conter o

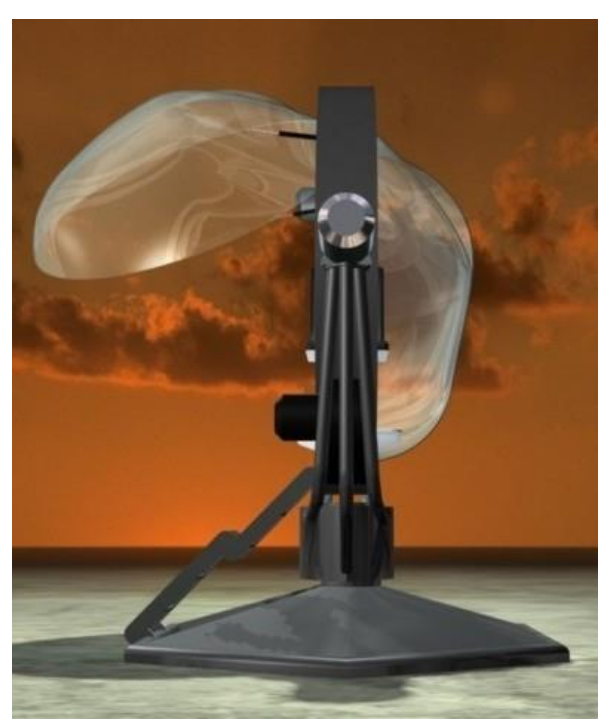
assento, pedais, painéis, manche e coletivo, dentre outros, solidária a d) um anel interno que gira segundo o eixo $\mathrm{C}$ em relação ao anel externo, com movimentos combináveis conforme a atitude da aeronave em simulação, a fim de transmitir movimentos de arfagem, rolagem e guinada.

A transmissão de dados é sem fio em alta velocidade, totalmente sincronizado com os eventos mecânicos do processo de simulação interativo com o piloto virtual, um processador gráfico gera as imagens do cenário de vôo projetado em um HMD (Helmet Mounted Display) estereoscópico, equipado com microfone, fones auriculares e também um dispositivo rastreador de movimentos para identificar, orientar e apresentar as imagens de acordo com o ponto de vista identificado, permitindo a simulação de procedimentos de vôo em variadas condições ambientais e meteorológicas, como já ocorre em específicos softwares simuladores de vôo.

Fig. 1 - Vista lateral do simulador.

Sistemas de acionamento de alta dinâmica são aplicados de modo a obter movimentos sobre as partes móveis, configurando-se na inédita concepção de todo sistema. Softwares de simulação coordenam os

\footnotetext{
${ }^{1}$ Projeto de Pesquisa CEART/UDESC

${ }^{2}$ Orientador, Professor do Departamento de Design

${ }^{3}$ Bolsista PMUC/FAPESC

${ }^{4}$ Bolsista de Iniciação Tecnológica Industrial - ITI-A/CNPq, mestrando em Engenharia Mecânica - UFSC

${ }^{5}$ Bolsista de Desenvolvimento Tecnológico Industrial - DTI-G/CNPq, mestrando em Design - Politécnico de Milão

${ }^{6}$ Bolsista de Desenvolvimento Tecnológico Industrial - DTI-G/CNPq
}

DAPesquisa, Florianópolis, v.2, n.4, p. 355-360, 2007. 
movimentos de todo o equipamento, com o objetivo, nos limites tecnológicos atuais, de proporcionar a máxima imersão do piloto ao ambiente virtual da aeronave, que comandará as ações fisicamente através do manche, pedais e de uma luva (data glove), que promoverá a interação manual do piloto às superfícies de comando (painéis). As interações orais, auditivas e visuais com o ambiente virtual se darão pelo uso do HMD.

\section{Procedimentos metodológicos}

Para o alcance dos resultados propostos à pesquisa com a contribuição do design, foram traçados procedimentos metodológicos, quais sejam: a) revisão bibliográfica sobre RV imersiva; b) estudo dos estímulos sensoriais e das forças a que os pilotos estão sujeitos na condução de aeronaves; c) documentação de parâmetros dimensionais de um helicóptero Esquilo; d) adaptação ergonômica do interior do simulador; e) redesign do interior do Simulador de vôo, que permite uma sensação mais próxima do ambiente real; f) adequação morfológica do simulador; g) modelagem e apresentação do simulador em ambiente virtual 3D, em adição aos cumpridos em etapa anterior e, dentre estes, os aprofundados nesta ação: a) adequação de procedimentos metodológicos em design para a proposição das soluções finais ao objeto da pesquisa; $b$ ) investigação dos problemas ergonômicos evidenciados e seus impactos nos campos materiais e produtivos;

c) preparação das especificações ergonômicas para a melhor interação homem x módulo simulador; d) análise e seleção de materiais e processos produtivos; e) planificação, com base nos resultados anteriores, do projeto contendo especificações, requisitos e restrições gerais para o produto.

Concluída a revisão bibliográfica, formalizou-se a adequação de procedimentos metodológicos para o desenvolvimento das soluções finais. Dentre alguns dos procedimentos investigados, está a TRIZ, sigla russa para Teória Rechénia Izobretátelskih Zadátchi (Teoria da Solução Inventiva de Problemas), método sistemático dirigido ao fator humano, orientada à investigação para a solução de problemas. Foram testados seus princípios básicos, como: heurísticas, baseadas em patentes; análises de conseqüências naturais como situações problemáticas e; a investigação e aplicação de saberes relativos ao campo que envolve o problema a ser solucionado, neste caso, a ergonomia.

Estes procedimentos foram eficazes para a evolução da pesquisa e o alcance de resultados A orientação da TRIZ ao ser humano ocorre por suas heurísticas serem dirigidas ao uso humano, é eficaz na conceituação de soluções, considerando o problema, a investigação e a solução como elementos de um sistema.

Iniciaram-se, então, os estudos dos estímulos sensoriais e das forças a que os pilotos estão sujeitos na condução de aeronaves. A partir de então, em atividade de campo, foi efetuado o levantamento fotográfico e dimensional, aliado às análises antropométricas, da cabine de um helicóptero Esquilo da série AS350, no esquadrão da Polícia Militar do Estado de Santa Catarina, possibilitando a mais adequada configuração funcional da cabine do simulador.

\section{Resultados}

As adequações antropométricas determinaram o redimensionamento da cabine que, ampliada, necessitava de um acréscimo de materiais para a sua configuração e, indesejavelmente, o aumento de massa necessitaria de maior potência para o acionamento eletro-mecânico, já criteriosamente dimensionado pela equipe de engenharia.

As alternativas centralizaram-se na racionalização de materiais para o garfo de acionamento rotacional, pela substituição das pesadas chapas metálicas por estruturas tubulares, uma opção que reduziria significativamente a massa deste elemento sem comprometer, a princípio, a resistência mecânica do componente e, objetivando a confirmação das soluções propostas - no que tange aos aspectos de resistência mecânica, foram aplicados recursos computacionais para testar a viabilidade material e estrutural. As soluções de projeto selecionadas foram modeladas virtualmente com o software Solidworks e testadas com esforços superiores aos que estariam submetidas no uso esperado, para este fim, foi utilizado o software Cosmos Express.

O quadro 1 a seguir, apresentado em versão resumida dos memoriais descritivos, indica os materiais e componentes especificados para o projeto tal como configurado. Destacam-se o aço cromo molibidênio SAE 4130 e o alumínio 6065, ambos de freqüente aplicação aeronáutica, que se em seus deméritos possuem elevado custo, contam com considerável resistência mecânica, propriedade que os habilita à redução de peso, no caso do aço pela possibilidade de ser utilizado em espessuras muito inferiores a aços comuns, como também no alumínio, pois que dada a alta maleabilidade das ligas comuns, não seria próprio para o uso em componentes que dependam de alta resistência a deformações. O elevado custo comparativo destes materiais,

DAPesquisa, Florianópolis, v.2, n.4, p. 355-360, 2007. 
justifica-se no projeto pela necessidade de baixo peso, o que favorece a utilização dos servo-motores de reduzida potência que, equipamentos de alta dinâmica, possuem custo proporcionalmente mais elevado que os materiais aplicados, elevam-se assim os custos dos materiais, mantendo-se relativamente baixo o custo global do módulo simulador por uma motorização menos onerosa, potencializando-se a confiabilidade de todo o sistema. Objetivou-se também a otimização e racionalização no uso de materiais pelo dimensionamento dos componentes, além das necessidades funcionais do simulador, pelo máximo aproveitamento de chapas e tubos de acordo com as dimensões comerciais destes materiais.

\begin{tabular}{|c|c|c|c|}
\hline ITEM & MATERIAL & QTDE & OUTRAS INFORMAÇÕES \\
\hline \multicolumn{4}{|l|}{ BASE } \\
\hline Estrutura & $\begin{array}{l}\text { Tubo de aço SAE } 4130 \text { red. Ø 3" esp. } \\
3,0 \mathrm{~mm}\end{array}$ & $19,5 \mathrm{~m}$ & \multirow{3}{*}{$\begin{array}{l}\text { A carcaça em chapas de aço } \\
\text { será soldada à estrutura tubular, } \\
\text { desta forma criando uma } \\
\text { unidade, que será fixa ao solo, } \\
\text { com o auxílio de uma sapata em } \\
\text { concreto. }\end{array}$} \\
\hline Carcaça & Chapa de aço SAE 4130 esp. 3/16" & $3,5 \mathrm{~m}^{2}$ & \\
\hline $\begin{array}{l}\text { Compartimento do } \\
\text { motor }\end{array}$ & Chapa de aço SAE 4130 esp. 3/16" & $0,7 \mathrm{~m}^{2}$ & \\
\hline \multicolumn{4}{|l|}{ GARFO } \\
\hline Estrutura central & Chapa de aço SAE 4130 esp. 3/8" & $1,0 \mathrm{~m}^{2}$ & \multirow{3}{*}{$\begin{array}{l}\text { Chapa calandrada e soldada. } \\
\text { Tubos soldados à estrutura } \\
\text { central e aos apoios do motor. }\end{array}$} \\
\hline Braços & $\begin{array}{l}\text { Tubo de aço SAE } 4130 \text { red. } \varnothing 2 " \text { esp. } \\
3,35 \mathrm{~mm}\end{array}$ & $11,5 \mathrm{~m}$ & \\
\hline Apoio para motor & Chapa de aço SAE 4130 esp. 3/8" & $\begin{array}{l}0,038 \\
\mathrm{~m}^{2}\end{array}$ & \\
\hline \multicolumn{4}{|l|}{ CONJUNTO DE ANÉIS } \\
\hline \multicolumn{4}{|c|}{$\begin{array}{l}\text { Ampliação em } 18 \% \text { no diâmetro, com o objetivo de prover o espaço necessário para o uso; além da alteração } \\
\text { no posicionamento do assento, visando um maior conforto e melhor aproveitamento do espaço; eliminação de } \\
\text { estruturas excedentes e resolução da configuração e alocação do painel, mantendo-se os materiais e dimensões } \\
\text { básicas especificados no ante-projeto. }\end{array}$} \\
\hline \multicolumn{4}{|l|}{ CABINE } \\
\hline Bolha & Policarbonato & $\begin{array}{l}3,77 \mathrm{~m}^{2} \\
\mathrm{p} / \\
\text { molde }\end{array}$ & \multirow{3}{*}{$\begin{array}{l}\text { Para a confecção da bolha será } \\
\text { necessária a utilização de um } \\
\text { molde. Para a produção da } \\
\text { estrutura interna serão } \\
\text { utilizados os processos de } \\
\text { usinagem e solda. }\end{array}$} \\
\hline $\begin{array}{l}\text { Sistema de } \\
\text { amortecimento da porta }\end{array}$ & Amortecedor pneumático & 2 un. & \\
\hline Estrutura interna & Chapa de alum. aer. 6065 esp. 3/8" & $1,5 \mathrm{~m}^{2}$ & \\
\hline
\end{tabular}

Quadro 1 - Planilha descritiva de materiais a serem utilizados no simulador.

Com a viabilidade das soluções selecionadas, alcançou-se o cumprimento das especificações e requisitos ergonômicos planificados no projeto, dando-se prosseguimento à reconstrução de modelos virtuais, a preparação e finalização da documentação descritiva.

O resultado alcançado não interferiu nas soluções de engenharia propostas antecipadamente ao projeto, como os acionamentos eletro-mecânicos especificados, sua configuração manteve-se inalterada apesar de toda a interferência necessária ao mais adequado ajuste ergonômico, tanto para o uso final, a pilotagem, quanto às ações de produção, de manutenção e de customização, principalmente nos meios de acesso e no interior da cabine, esta que é personalizável aos postos de comando de cada aeronave ou grupo de aeronaves, segundo as condições próprias de pilotagem, especialmente pela utilização de acessórios como banco, painéis, manche e pedais, para o que permite total customização de montagem. 

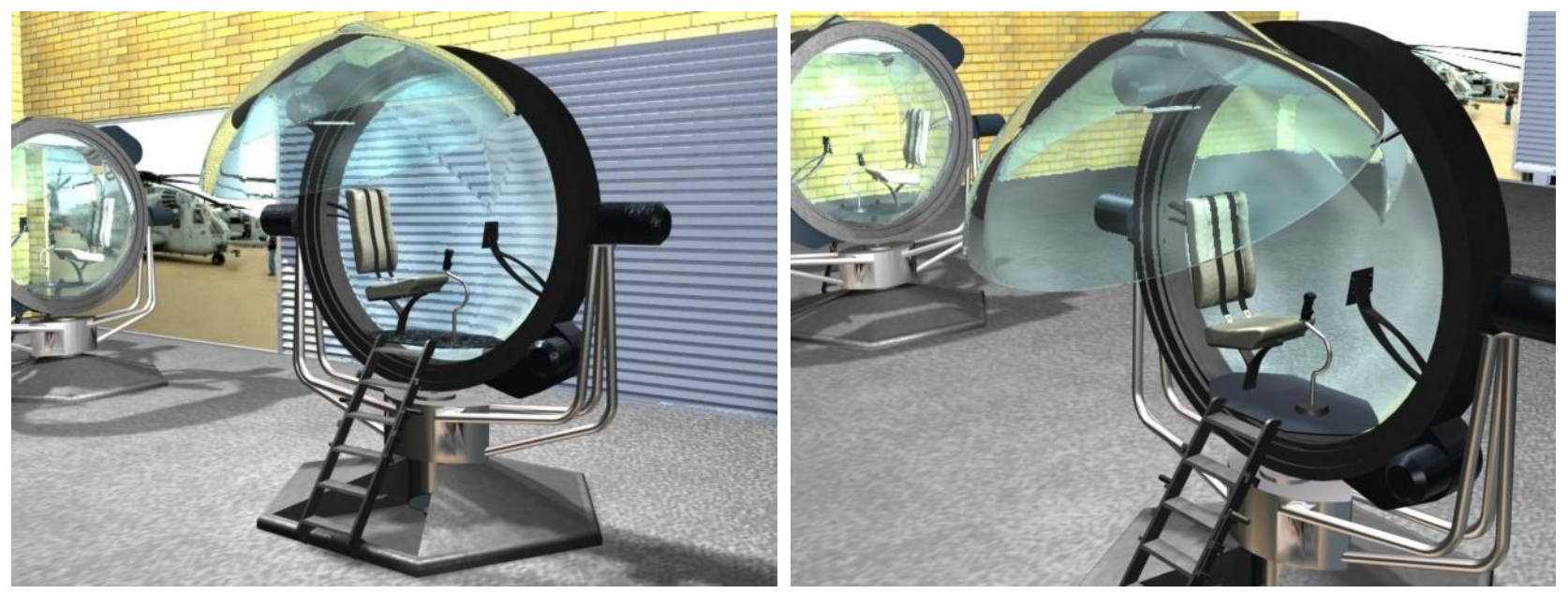

Fig. 2 - Renderizações do modelo virtual do projeto final.

A figura 2 apresenta renderings do módulo simulador resultado deste projeto, produzidos com o software 3DMax, em uma configuração básica de assento e manche adequada a helicópteros esquilo da série AS350 (fig. 3), sem painéis e pedais que, como descrito anteriormente, serão configurados de acordo com as customizações necessárias à simulação de aeronaves diversas (civis, militares, aviões ou helicópteros). Notese nesta representação a inclusão, dentre outros elementos, da escada escamoteável de acesso, inexistente no projeto original.

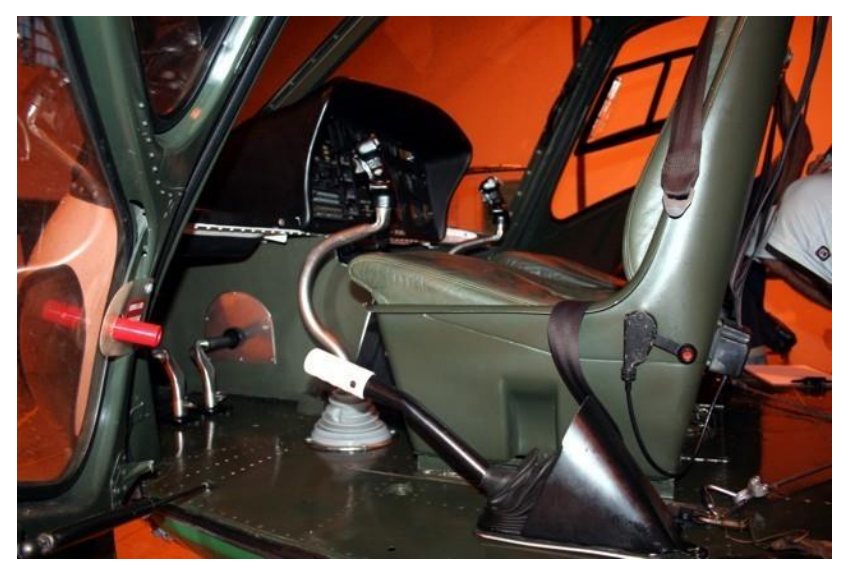

Fig. 3 - Foto de interior do helicóptero Esquilo AS350.

Uma série de itens inexistentes no ante-projeto foi incluída, todos estes itens voltados à otimização ergonômica do simulador, como também a solução adotada para o fechamento da bolha (acesso) na cabine, agora configurada em asa. Outra incorporação ao projeto, como resultado das avaliações ergonômicas, é o formato da própria bolha da cabine, em seção transversal ovalóide e não mais esférica, possibilitando maior amplitude aos movimentos dos membros superiores do piloto, necessários para o acesso aos painéis de comando.

\section{Considerações finais}

Consideram-se significativos os resultados, na medida em que apresentam soluções aos desafios que se estabeleciam nos limites de viabilização tecnológica para a adequação ergonômica, para a humanização da tecnologia envolvida, levando à corroboração dos resultados obtidos e do processo metodológico de projeto utilizado.

Destaca-se que o projeto não tratou, somente, de adequar ao módulo simulador os componentes de interação humana das aeronaves. O relacionamento humano com o ambiente virtual, a realidade virtual, exige soluções próprias, não apenas para simular uma situação real, mas por caracterizar-se em uma interação que 
efetivamente ocorrerá com um ambiente próprio, que é físico e virtual simultaneamente, gerando estímulos sensoriais e percepções singulares que, além disso, deverão simular percepções de naturezas distintas das que possam estar sendo vivenciadas.

Ainda que em imersão no ambiente virtual, o usuário (piloto) mantém contato físico com o equipamento simulador, experimentando sensações próprias de uma interação real que de modo algum poderão conflitar com as sugeridas pela realidade virtual imposta, em outras palavras, é inaceitável a ocorrência de percepções discrepantes a partir dos estímulos sensoriais experimentados pelos sentidos envolvidos com os ambientes real e virtual. A literatura relata distúrbios orgânicos em simuladores de vôo por conflitos desta natureza, náuseas são comuns, onde pilotos experientes são mais propensos do que usuários que nunca pilotaram uma aeronave real, em razão daqueles estarem mentalmente condicionados a esperar esforços corpóreos como respostas a determinadas atitudes de vôo, esforços que não ocorrem nos simuladores convencionais, por estarem, na realidade, em solo e à velocidade "zero".

Contudo, o desenvolvimento da pesquisa no que se refere ao design de simuladores de movimentos em realidade virtual demonstra que, nesta área, muito ainda deve ser alcançado, sobretudo quanto aos aspectos ergonômicos, pois que se está avançada ao enfoque da engenharia, concentrada nos aspectos de viabilização mecânica, eletrônica e de software, no que concerne à interação humana, foco dos estudos em design e ergonomia, carece de profundidade científica e tecnológica para o favorecimento da imersão em RV. Entrevistas efetuadas com pilotos e instrutores de vôo da Aeronáutica e da Marinha, no decorrer da pesquisa, surpreendentemente revelaram a opinião comum de que é mais próximo do real pilotar virtualmente aeronaves nos seus computadores domésticos do que nos simuladores de vôo existentes disponibilizados a eles. Para esta questão, a hipótese levantada aqui foi: os simuladores que procuram promover a imersão em RV estão presos ao paradigma de simular os movimentos das aeronaves e não de simular os movimentos que gerariam os esforços a que os pilotos estariam submetidos na realidade, ainda que tais esforços viessem a ocorrer em intensidade menor, mas que, contudo, fossem suficientes para não gerar estímulos contrários e, portanto, discrepantes. Deve-se ter em mente que em simulações imersivas em RV o piloto não possui contato visual ou auditivo com o ambiente real.

Neste sentido, a RV também pode ser caracterizada pela coexistência integrada de dois conceitos principais a este tema, são eles os de imersão e interação (MORIE, 1994). A idéia de imersão está ligada ao sentimento de fazer parte do ambiente. Normalmente, um sistema imersivo é obtido com o uso do HMD; sistemas imersivos baseados em salas com projeções das visões nas paredes, teto, e piso (CRUZ-NEIRA, 1992). Além do fator visual, dispositivos ligados aos demais sentidos também são importantes para o sentimento de imersão, como o som (BEGAULT, 1994), o posicionamento automático da pessoa e dos movimentos da cabeça, controles reativos, etc. (GRADECKI, 1995). A visualização de uma cena 3D em um monitor é considerada não imersiva. Dessa forma, tem-se a conceituação de RV imersiva e não imersiva (LESTON, 1996).

Os resultados alcançados em termos de projeto industrial, revelam uma significativa evolução no segmento de simulação aeroespacial, conta com soluções para problemas de interação humana aos ambientes físico e virtual que envolvem o relacionamento com o simulador, de acordo com os paradigmas estabelecidos pela evolução tecnológica neste campo. O que se apresenta é a simulação adequada de sensações físicas mais correspondentes às percepções próprias de um vôo simuladas em RV.

Têm-se, por fim, que um equipamento simulador de vôo dificilmente poderá reproduzir os esforços a que os pilotos se submetem em vôos reais com igual intensidade, porém, em razão da gama de movimentos possíveis, antecipa-se com estes resultados o alcance da reprodução de esforços que possam, através da configuração de movimentos utilizando apenas a força gravitacional, corresponder mais proximamente às percepções e reações vivenciadas na realidade, evitando deste modo a produção de estímulos contraditórios e, por isso, inaceitáveis.

\section{Referências Bibliográficas}

ABREU, Romeu C. L. Análise de valor: um caminho criativo para a otimização dos custos e do uso dos recursos, Rio de Janeiro: Qualitymark, 1996.

Araújo, R. B. Especificação e análise de um sistema distribuído de realidade virtual. São Paulo: Departamento de Engenharia de Computação e Sistemas Digitais, Escola Politécnica da Universidade de São Paulo, 144 p., tese de doutorado, jun-1996.

BACK, Nelson. Metodologia de Projeto de Produtos Industriais, Rio de Janeiro: Guanabara Dois, 1983. BEGAULT, D. R. 3-D Sound for virtual reality and multimedia. Cambridge, MA: Academic Press, 1994.

DAPesquisa, Florianópolis, v.2, n.4, p. 355-360, 2007. 
BROCKA, Bruce \& BROCKA, Suzanne M. Gerenciamento da Qualidade, São Paulo: Ed. Makron Books, 1994.

CRUZ-NEIRA, C. et al. The CAVE audio visual experience automatic virtual environment. In:

Communication of the ACM, 35(6):64-72, jun-1992.

CSILLAG, João M. Análise do valor, São Paulo: Atlas, 1995.

GOMES FILHO, João. Ergonomia do objeto. São Paulo: Escrituras, 2003.

GRADECKI, J. The virtual reality construction kit. Hoboken, NJ, EUA: John Wiley \& Sons, 1995.

IIDA, I. Ergonomia: projeto e produção, São Paulo: Ed. Edgard Blücher, 5 ed, 1998.

JURAN, J. M. \& GRYNA, Frank M. Juran - Controle da Qualidade. Vol. III - Ciclo dos Produtos: do

Projeto à Produção, São Paulo: Ed. Makron Books, 4 ed, 1992.

LESTON, J. Virtual reality: the it perspective. In: Computer Bulletin, p. 12-3, jun - 1996.

MORIE, J. F. Inspiring the future: merging mass communication, art, entertainment and virtual environment. In: Computer Graphics, 28(2):135-138, maio-1994.

REIS, Alexandre Amorim dos. Critérios para Avaliação de um Design Industrial, Novo Hamburgo: Anais do $4^{\circ}$ Congresso Brasileiro de P\&D em Design, 2000, p. 931-8.

. Design e matéria: uma fronteira que nunca existiu. In: Revista abcDesign, Curitiba. n. 02, mar.

2002, p. 12-6. . Matéria, forma e função: a influência material no design industrial. Tese de Doutorado,

Florianópolis: Universidade Federal de Santa Catarina, 2003. . A interação entre as ciências para a pesquisa em design, São Paulo: FAAP/Anais do $6^{\circ}$ Congresso

Brasileiro de P\&D em Design, 2004.

SANDERS, Mark S. \& Mc CORMICK, Ernest J. Human Factors In Engineering and Design, New York:

McGraw-Hill, 1993

SANTOS, N. Manual de análise ergonômica do trabalho, Curitiba: Gênesis, 1995.

STERNBERG, R. J. Psicologia Cognitiva, Porto Alegre: Artmed, 2000.

VICENTE, Kim. The Human Factor: Revolutionizing the Way People Live With Technology, Toronto:

Routledge, 2004. 